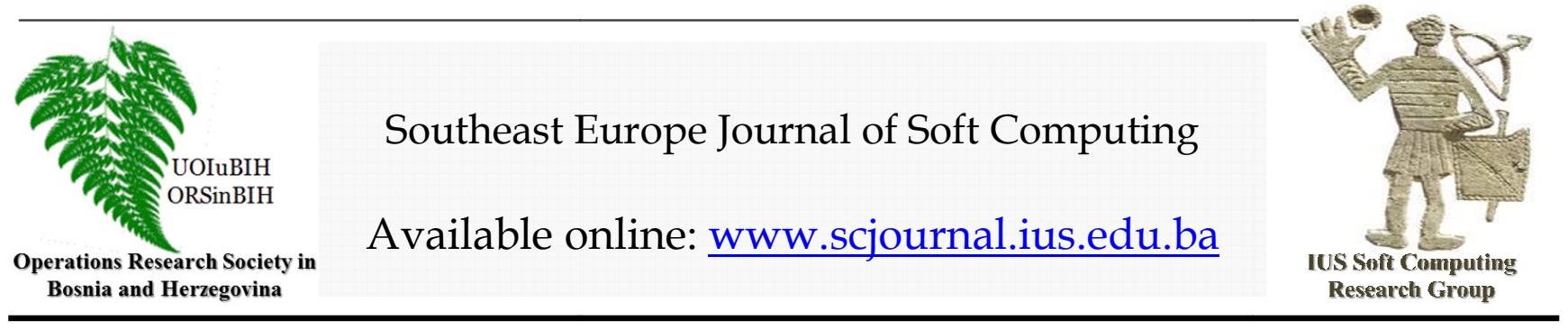

\title{
Conformational Parameters for Amino Acids in Helical, B-Sheet, and Random Coil Regions Calculated from Proteins: After 40 Years
}

\author{
Mehmet Can \\ International University of Sarajevo, Faculty of Engineering and Natural Sciences, Hrasnicka Cesta 15, Ilidža \\ 71210 Sarajevo, Bosnia and Herzegovina \\ mcan@ius.edu.ba
}

\section{Article Info}

Article history:

Article received on February 2015

Received in revised form March 2015

Keywords:

Protein structural classes, Secondary structure; Conformation of proteins; Statistical methods

\begin{abstract}
Forty years ago, Peter Y. Chou and Gerald D. Fasman (1974a), relying on the information from fifteen proteins calculated $\alpha$ helix, $\beta$-sheet, and coil conformational parameters, $\mathrm{P}_{\alpha}, \mathrm{P}_{\beta}$, and $\mathrm{P}_{c}$, for the 20 naturally occurring amino acids from the frequency of occurrence of each amino acid residue in the $\alpha, \beta$, and coil conformations. Secondary structure of these 15 proteins had been determined by X-ray crystallography. Although the accuracy could not go over to the level of $60 \%$ too much, these values utilized for a long time to provide a simple procedure, devoid of complex computer calculations, to predict the secondary structure of proteins from their known amino acid sequences. In the same article of Peter Y. Chou and Gerald D. Fasman, a detailed analysis of the helix and $\beta$-sheet boundary residues in proteins provided amino acid frequencies at the $\mathrm{N}$ and $\mathrm{C}$-terminal ends which were used to delineate helical and $\beta$ regions. Charged residues are found with the greatest frequency at both helical ends, but they were mostly absent in $\beta$-sheet regions. In the same article a mechanism of protein folding was proposed, whereby helix nucleation starts at the centers of the helix where the $\mathrm{P}_{\alpha}$ values are highest, and propagates in both directions, until strong helix breakers where $\mathrm{P}_{\alpha}$ values are lowest, terminate the growth at both ends. Similarly, residues with the highest $\mathrm{P}_{\beta}$ values will initiate $\beta$ regions and residues with the lowest $\mathrm{P}_{\beta}$ values will terminate $\beta$ regions. The helical region with the largest $P_{\alpha}$ was proposed as the site of the first fold during protein renaturation. The mechanism whereby proteins fold into their native conformation, capable of biological activity, has been a long sought after goal. With the elucidation of the three-dimensional structure of many proteins through $\mathrm{X}$-ray crystallography, a new momentum has been given to understanding the factors governing this complex assembly of polypeptide chains. In this paper, using similar statistics from 20347 proteins, the level of reliability of formerly found results is discussed.
\end{abstract}




\section{INTRODUCTION}

The impetus for the prediction of protein conformation was initiated with studies on $\alpha$-amino acids. Helix formation in $\alpha$-amino acids is characterized by a cooperative process (Zimm and Bragg, 1959; Applequist, 1963) in which the Zimm-Bragg parameters $\sigma$ and s are defined respectively as the cooperativity factor for helix initiation, and the equilibrium constant for converting a coil residue to a helical state at the end of a long helical sequence. Potentiometric titration data on poly (L-glutamic acid) (Nagasawa and Holtzer, 1964) and poly(L-lysine) (Hermans, 1966a) gave $\mathrm{s}$ values of 1.25 and 1.15 , respectively, in aqueous solution at $25^{\circ} \mathrm{C}$. Since $\mathrm{s}=1$ corresponds to the critical value at which long chains substantially convert into the helical form (Zimm and Bragg, 1959), the greater than unity s values for poly $(\mathrm{G} 1 \mathrm{u})$ and poly(Lys) (both in the un-ionized form) indicate that these two homopolymers form stable helices; this has been confirmed by optical studies.

An analysis of all 20 amino acids in 15 proteins was presented in Chou and Fasman (1974a), whereby the frequency of their occurrence in various conformational states is compared with the experimental Zimm-Bragg $\sigma$ and s parameters. Boundary residues of helical and $\beta$-sheet sections were analyzed, and yield clues for the termination of these conformational regions. The helix and $\beta$ conformational parameters provided a quantitative measure of regions in proteins with the highest helical and $\beta$-sheet potential, and may be useful in understanding protein folding mechanisms. These parameters had been used with limited success in predicting protein secondary conformation from known amino acid sequences along years that follow.

\section{METHOD}

Secondary structures of proteins are obtained in the form of the x-ray analyses in three conformations helix " $h "$, sheet "s" , and others ".". Others are interpreted as coils "c".

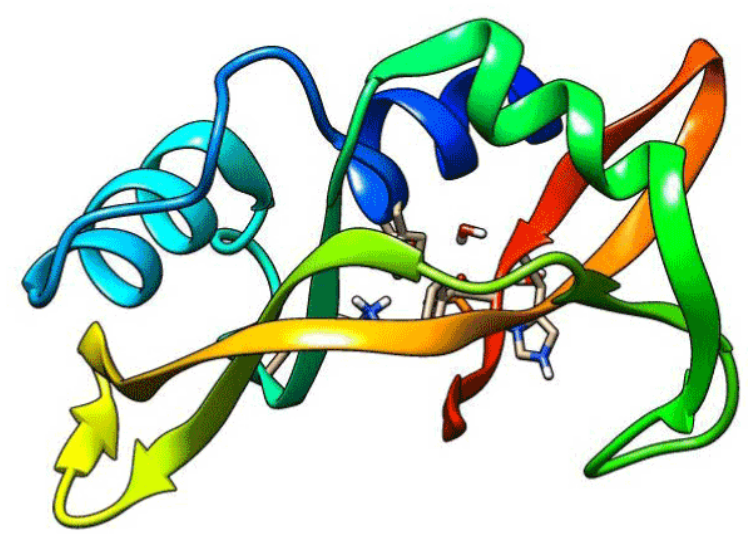

Figure 1. $\alpha$-helices, $\beta$-sheets, and coils on the same picture

\section{Symbols for Amino Acids}

Proteins are chains in the three dimensional space built from smaller chemical molecules called amino acids. Thereare 20 different amino acids. Each of them is denoted by a different letter in the Latin alphabet as shown below.

TABLE1. Names and symbols of 20 amino acids

\begin{tabular}{|l|l|l|l|}
\hline$\#$ & Amino acid & Chemical & alphabet \\
\hline 1 & Alanine & Ala & A \\
\hline 2 & Arginine & Arg & R \\
\hline 3 & Asparagine & Asn & N \\
\hline 4 & Aspartic acid & Asp & D \\
\hline 5 & Cysteine & Cys & C \\
\hline 6 & Glutamine & Gln & Q \\
\hline 7 & Glutamic acid & Glu & E \\
\hline 8 & Glycine & Gly & G \\
\hline 9 & Histidine & His & H \\
\hline 10 & Isoleucine & Ile & I \\
\hline 11 & Leucine & Leu & L \\
\hline 12 & Lysine & Lys & K \\
\hline 13 & Methionine & Met & M \\
\hline 14 & Phenylalanine & Phe & F \\
\hline 15 & Proline & Pro & P \\
\hline 16 & Serine & Ser & S \\
\hline 17 & Threonine & Thr & T \\
\hline 18 & Tryptophan & Trp & W \\
\hline 19 & Tyrosine & Tyr & Y \\
\hline 20 & Valine & Val & V \\
\hline & &
\end{tabular}

Based on the protein chain it is easy to create its relevant sequence of amino acids replacing an amino acid in chainby its code in Latin alphabet. As a result a word on the amino acids' alphabet is received. This word can be calleda protein primary structureon the condition that letters in this word are in the same order as amino acids in theprotein chain are.

A secondary structure of a protein is a subsequence of amino acids coming from the relevant protein. Thesesub chains form in the three dimensional space regular structures which are the same in shape for differentproteins. In the analysis, a similar representation for the secondary structures as for the primary oneshas been used. A secondary structure is represented by a word on the relevant alphabet of secondary structures - eachkind of a secondary structure has its own unique letter $\alpha$-helix, $\mathrm{H} ; \beta$-sheetS, and coil $\mathrm{C}$. An alphabet of secondary structures consisting of threedifferent secondary structures has been considered in the analysis.

\section{Pioneering Research}

Chou and Fasman (1974a) made a survey on the following 15 proteins whose amino acid sequences and conformations via X-ray crystallography are known: carboxypeptidase A (Quiocho and Lipscomb, 1971), a-chymotrypsin (Blow, 1969), cytochrome 115 (Mathews er al., 1972), elastase (Shotton and Watson, 1970), ferricytochrome c (Dickerson et al., 1971), a and P-hemoglobin 
(Perutz et of., 1968), insulin (Blundell et al., 1972), lysozyme (Blake et al., 1967), myogen (Nockolds et al., 1972), myoglobin (Kendrew et al., 1961), papain (Drenth et al., 1971), ribonuclease S (Wyckoff et al., 1970), staphylococcal nuclease (Arnone et al., 1971), and subtilisin BPN (Wright et al., 1969).

\section{Helix, $\beta$-sheet, and coil regions}

The amino acid residues in the helix, $\beta$-sheet, and coil regions of these 15 proteins were tabulated in Table 2. (TABLE 2 of Chou and Fasman (1974a)). It should be noted that the $\beta$-sheet residues differ slightly from those reported earlier (Chou and Fasman, 1973) due to more recent detailed X-ray diffraction analysis references cited above. Where the $\beta$ regions were not specified explicitly in the original papers, as in the case of chymotrypsin, elastase, and ribonuclease $\mathrm{S}$, the schematic diagrams showing hydrogen bonding in these proteins were used to delineate the $\beta$-sheet regions. Residues at $\beta$ bends which did not show hydrogen bonding were not included in the $\beta$ sheet regions. All regions designated as helical (alicyll, 310 , distorted helix) by the X-ray crystallographic studies have been included as helical residues in Table 2. Despite minor changes in some helical regions, based on the latest $\mathrm{X}$-ray studies denoted in a following paper, the analysis did not significantly alter the calculated helix parameters so that the helical residues listed in Table 2 are identical with those reported earlier (Chou and Fasman, 1973).

TABLE 2: Amino acid residues in the helix, inner helix, $\beta$ sheet, and coil regions of 15 proteins in Chou and Fasman, 1974a.

\begin{tabular}{|l|l|l|l|l|l|}
\hline A. Acid & AA & H & In H & In $\beta$ & In Coil \\
\hline Ala & 228 & 119 & 62 & 38 & 71 \\
\hline Arg & 78 & 22 & 9 & 12 & 44 \\
\hline Asn & 133 & 35 & 12 & 15 & 83 \\
\hline ASP & 111 & 39 & 10 & 15 & 57 \\
\hline CYS & 54 & 15 & 3 & 12 & 27 \\
\hline Gin & 95 & 40 & 16 & 20 & 35 \\
\hline Glu & 113 & 62 & 28 & 5 & 46 \\
\hline GlY & 232 & 45 & 22 & 32 & 155 \\
\hline His & 74 & 33 & 11 & 9 & 32 \\
\hline Ile & 106 & 38 & 22 & 29 & 39 \\
\hline Leu & 196 & 94 & 64 & 41 & 61 \\
\hline LYS & 175 & 67 & 34 & 22 & 86 \\
\hline Met & 28 & 12 & 6 & 8 & 8 \\
\hline Phe & 82 & 33 & 16 & 18 & 31 \\
\hline Pro & 85 & 18 & 0 & 9 & 58 \\
\hline Ser & 202 & 57 & 24 & 25 & 120 \\
\hline Thr & 156 & 47 & 21 & 32 & 77 \\
\hline TrP & 44 & 18 & 10 & 9 & 17 \\
\hline Tyr & 100 & 22 & 10 & 22 & 56 \\
\hline Val & 181 & 74 & 44 & 51 & 56 \\
\hline Total & 2473 & 890 & 424 & 424 & 1159 \\
\hline
\end{tabular}

Before the time of Chou and Fasman, some surveys of helical and nonhelical residues had been performed, they were based on even fewer proteins (Cook, 1967; Kotelchuck et al., 1963; Ptitsyn, 1969; Finkelstein and Ptitsyn, 1971; Kabat and Wu, 1973a,b; Wu and Kabat, 1971, 1973). Hence, the analysis using 15 proteins containing 2473 residues should had more statistical reliability than earlier literature data. In Chou and Fasman 1974a in addition, the $\beta$-sheet regions of proteins as well as the helical and $\beta$-sheet boundary regions had been analyzed in greater detail. In Chou and Fasman 1974b, authors further improved their analysis.

\section{NORMALIZATION PROCEDURE}

In Chou and Fasman, 1974a, a normalization procedure had also been used to derive helix, $\beta$, and coil conformational parameters which can be used in predicting protein conformation. In this article the probability of finding the $\mathrm{j}$ amino acid residue in a protein is given by

$p_{j}=\frac{n_{j}}{\sum n_{j}}$

wheren $\mathrm{j}_{\mathrm{j}}$ is the number of $\mathrm{j}$ residues in proteins, and $\sum n_{j}$ is the total number of residues in proteins. The probability of finding the $\mathrm{j}$ residue in the conformational state, $\mathrm{k}$, of proteins is

$p_{j, k}=\frac{n_{j, k}}{\sum n_{j, k}}$

wheren $_{\mathrm{j}, \mathrm{k}}$ is the number of $\mathrm{j}$ residues in the $\mathrm{k}$ state and $\sum n_{j, k}$ is the total number of residues in the $\mathrm{k}$ state. The probability or frequency of occurrence of the $\mathrm{j}$ residue in the $\mathrm{k}$ state of proteins is

$f_{j, k}=\frac{n_{j, k}}{n_{j}}$

Therefore, the average frequency of finding the 20 amino acid residues in the $\mathrm{k}$ state of proteins, $\left\langle f_{k}\right\rangle$ can be written as

$\left\langle f_{k}\right\rangle=\frac{\sum f_{j, k}}{\sum j}=\frac{\sum n_{j, k}}{\sum n_{j}}$

where $\sum j=20$. When $\mathrm{f}$, is normalized by,$\left\langle f_{k}\right\rangle$ the conformational parameter $P_{j, k}$ of the $\mathrm{j}$ amino acid residue is

$P_{j, k}=\frac{f_{j, k}}{\left\langle f_{k}\right\rangle}$

Substituting eq 1-4 in (5) results in

$P_{j, k}=\frac{p_{j, k}}{p_{j}}$

Hence the conformational parameter of the $\mathrm{j}$ amino acid residue in the $\mathrm{k}$ state, $\mathrm{P}_{\mathrm{j}, \mathrm{k}}$ is equal to the probability of finding the $\mathrm{j}$ residue in the $\mathrm{k}$ state divided by the probability of finding the $\mathrm{j}$ residue in proteins. The $\mathrm{k}$ conformational state in proteins is either the $\alpha, \beta$, or 
random coil. Throughout the text the subscript $\mathrm{j}$ is omitted to aid in clarity.

\section{NORMALIZATION RESULTS}

To make a comparison with today's available data, we simplified the procedure and limited ourselves only amino acid residues in the helix, $\beta$-sheet, and coil regions in Table 2 of 15 proteins. When we apply the normalization in the above, Table 2 columns are replaced by the columns of Table 3.

Table 3: Normalized amino acid residues in the helix, $\beta$ sheet, and coil regions of 15 proteins in Chou and Fasman, 1974a.

\begin{tabular}{|c|c|c|c|}
\hline "O" & "H" & "E" & "C" \\
\hline "A & 0.52 & 0.17 & 0.31 \\
\hline "R" & 0.28 & 0.15 & 0.56 \\
\hline "N" & 0.26 & 0.11 & 0.62 \\
\hline "D" & 0.35 & 0.14 & 0.51 \\
\hline "C" & 0.28 & 0.22 & 0.50 \\
\hline "Q" & 0.42 & 0.21 & 0.37 \\
\hline "H" & 0.55 & 0.04 & 0.41 \\
\hline "G" & 0.19 & 0.14 & 0.67 \\
\hline "E" & 0.45 & 0.12 & 0.43 \\
\hline "I" & 0.36 & 0.27 & 0.37 \\
\hline "L" & 0.48 & 0.21 & 0.31 \\
\hline "K" & 0.38 & 0.13 & 0.49 \\
\hline "M" & 0.43 & 0.29 & 0.29 \\
\hline "F" & 0.40 & 0.22 & 0.38 \\
\hline "P" & 0.21 & 0.11 & 0.68 \\
\hline "S" & 0.28 & 0.12 & 0.59 \\
\hline "T" & 0.30 & 0.21 & 0.49 \\
\hline "W" & 0.41 & 0.20 & 0.39 \\
\hline "Y" & 0.22 & 0.22 & 0.56 \\
\hline "V" & 0.41 & 0.28 & 0.31 \\
\hline
\end{tabular}

\section{RESULTS AND DISCUSSION}

In Chou and Fasman, 1974a in addition to the helical regions, the $\beta$-sheet regions of proteins as well as the helical and $\beta$-sheet boundary regions had been analyzed in greater detail using 15 proteins containing 2473 residues. We wondered how today abundant data has changed these result. For comparison we only choose amino acid residues in the helix, $\beta$-sheet, and coil regions.

We visited several databases and collected data for 4341 108 residues which reside in 20347 non redundant proteins. Normalized results for amino acid residues in the helix, $\beta$-sheet, and coil regions of 20347 proteins are tabulated in Table 4.

Table 4: Normalized amino acid residues in the helix, $\beta$ sheet, and coil regions of 20347 proteins from several non redundant databases.

\begin{tabular}{|c|c|c|c|}
\hline "०" & "H" & "E" & "C" \\
\hline "A" & 0.51 & 0.16 & 0.33 \\
\hline "R" & 0.44 & 0.19 & 0.37 \\
\hline$" N "$ & 0.29 & 0.12 & 0.58 \\
\hline "D" & 0.33 & 0.11 & 0.56 \\
\hline "C" & 0.32 & 0.28 & 0.40 \\
\hline "Q" & 0.47 & 0.15 & 0.38 \\
\hline "H" & 0.30 & 0.19 & 0.50 \\
\hline "G" & 0.17 & 0.13 & 0.70 \\
\hline "E" & 0.50 & 0.14 & 0.37 \\
\hline "I" & 0.39 & 0.36 & 0.25 \\
\hline "L" & 0.49 & 0.23 & 0.28 \\
\hline "K" & 0.42 & 0.16 & 0.42 \\
\hline "M" & 0.43 & 0.20 & 0.37 \\
\hline "F" & 0.38 & 0.30 & 0.32 \\
\hline "P " & 0.19 & 0.09 & 0.72 \\
\hline "S" & 0.29 & 0.16 & 0.54 \\
\hline "T" & 0.28 & 0.25 & 0.47 \\
\hline "W" & 0.41 & 0.27 & 0.32 \\
\hline "Y" & 0.37 & 0.29 & 0.33 \\
\hline "V" & 0.33 & 0.40 & 0.28 \\
\hline
\end{tabular}

Percentage errors made in probabilities of amino acid residues in the helix, $\beta$-sheet, and coil regions of proteins are found as in Table 5 . 
Table 5: Percentage errors made in probabilities of amino acid residues in the helix, $\beta$-sheet, and coil regions.

\begin{tabular}{|c|c|c|c|c|}
\hline $\mathrm{O}$ & $\mathrm{H}$ & $\mathrm{E}$ & $\mathrm{C}$ & Overall \\
\hline$\%$ Error & 0.14 & 0.25 & 0.16 & 0.17 \\
\hline
\end{tabular}

These percentage errors would not make any difference if the most preferred states for amino acids were the same in two investigations. In Table 5, the most preferred states are shown in two investigation: $\mathrm{cf}$ is for Chou and Fasman, $1974 \mathrm{a}$, and ta for this article. 1 is for helix, 2 for $\beta$-sheet, and 3 for coil.

Table 6: The most preferred states for 20 amino acids are shown in two investigation: cf is for Chou and Fasman, 1974a, and ta for this article. 1 is for helix, 2 for $\beta$-sheet, and 3 for coil.

\begin{tabular}{|c|c|c|}
\hline 0 & $\mathrm{Cf}$ & ta \\
\hline A & 1 & 1 \\
\hline$R$ & 3 & 1 \\
\hline $\mathrm{N}$ & 3 & 3 \\
\hline $\mathrm{D}$ & 3 & 3 \\
\hline $\mathrm{C}$ & 3 & 3 \\
\hline$Q$ & 1 & 1 \\
\hline $\mathrm{H}$ & 1 & 3 \\
\hline G & 3 & 3 \\
\hline $\mathrm{E}$ & 1 & 1 \\
\hline I & 3 & 1 \\
\hline $\mathrm{L}$ & 1 & 1 \\
\hline K & 3 & 3 \\
\hline $\mathrm{M}$ & 1 & 1 \\
\hline$F$ & 1 & 1 \\
\hline $\mathrm{P}$ & 3 & 3 \\
\hline S & 3 & 3 \\
\hline $\mathrm{T}$ & 3 & 3 \\
\hline W & 1 & 1 \\
\hline$Y$ & 3 & 1 \\
\hline V & 1 & 2 \\
\hline
\end{tabular}

In this table we see that Arginine, Glutamic acid, Isoleucine, Tyrosine, and Valine changed their most preferable states. If we believe in statistics which rely on two thousand times larger data, wrong most preferable states for five amino acids among twenty is something tolerable.

\section{REFERENCES}

Applequist, J. (1963), On the helix-coil equilibrium in polypeptides. J. Chem. Phys. 38,934-941.

Arnone, A,, Bier, C. J., Cotton, F. A., Day, V. W., Hazen, E. E., Jr., Richardson, D. C., Richardson, J. S., and, Yonath, A. (1971), A high resolution structure of an inhibitor complex of the extracellular nuclease of staphylococcus aurous, J. Biol. Chem. 246, 2302.

Blake, C. C. F., Mair, G. A., North, A. C. T., Phillips, D. C., and Sarma, V.R. (1967), On the conformation of the hen egg-white lysizyme, Proc. Roy. Soc., B 167,365-377.

Blow, D. M. (1969), The Study of a-Chymotrypsin by XRay Diffraction, Biochem. J. 112, 261-268.

Blundell, T. L., Cutfield, J. F.,Dodson, E. J., Dodson, G. G., Hodgkin, D. C., and Mercola, D. A. (1972), The crystal structure of rhombohedral 2 zinc insulin, Cold Spring Harbor Symp. Quant. Biol. 36, 233-241.

Chou, P. Y., and Fasman, G. D.(1973),Structural and functional role of Leu residues in proteins, J. Mol. Biol. 74, 263-281.

Chou, P. Y., and Fasman, G. D. (1974a), Conformational Parameters for Amino Acids in Helical, $\beta$-Sheet, and Random Coil Regions Calculated from Proteins, Biochemistry 13, 211-222.

Chou, P. Y., and Fasman, G. D. (1974b),Prediction of Protein Conformation, Biochemistry 13,222-245.

Cook, D. A. (1967), The relation between amino acic sequence and protein conformation, J. Mol. Bid. 29, 167171.

Dickerson, R. E., Takano, T., Eisenberg, D., Kallai, O. B., Samson, L., Cooper, A., and Margoliash, E. (1971), General features of horse and bonito proteins at $2.8 \mathrm{~A}^{\mathrm{O}}$ resolution, J. Biol. Chem. 246, 1511-1535.

Drenth, J., Jansonius, J. N., Koekoek, R., and Wolthers, B. G. (1971), The structure of papain. Adv Protein Chem. 1971;25:79-115.

Finkelstein, A. V., and Ptitsyn, 0. B. (1971), Statistical analysis of the correlation among amino acid residues in helical, beta-structural and non-regular regions of globular proteins, J. Mol. Biol. 62, 613-624.

Hermans, J. (1966),Experimental Free Energy and Enthalpy of Formation of the $\alpha$ Helix, J. Phys. Chem. 70, 510-515.

Kabat, E. A., and Wu, T. T. (1973a),The influence of nearest neighbor amino acids residues on aspects of secondary structure proteins: attempts to location of ahelices, and b-sheets, Biopolymers 12, 751-774.

Kabat, E. A., and Wu, T. T. (1973b), The influence of nearest neighbor amino acids on the conformation of the middle amino acids of the proteins. Comparison of the predicted and experimental determination of b-sheets in conconavalin A, Proc. Natl. Acad. Sci. U.S. 70,1473-1477. 
Kendrew, J. C., Watson, H. C., Strandberg, B. E., Dickerson, R. E., Phillips, D. C., and Shore, V. C. (1961), The amino-acid sequence X-ray methods, and its correlation with chemical data, Nature (London) 190, 666670.

Kotelchuck, D., Dygert, M., and Scheraga, H. A. (1969), The influence of short-range interactions on protein conformation. III. Dipeptide distributions in proteins of known sequence and structure, Proc. Natl. Acad. Sci. U.S. 63,615-622.

Mathews, F. S., Levine, M., and Argos, P. (1972), Threedimensional Fouriersynthesis of calfliver cytochrome b5 at $2.8 \mathrm{~A}^{\mathrm{o}}$ resolution, J. Mol. Biol. 64,449-464.

Nagasawa, M., and Holtzer, A. (1964), The Use of the Debye-Hckel Approximation in the Analysis of Protein Potentiometric Titration Data, J. Amer. Chem. Soc. 86, 531-538.

Nockolds, C. E., Kretsinger, R. H., Coffee, C. J., and Bradshaw, R. A. (1972), Structure of a calcium-binding carp myogen, Proc. Nut. Acad. Sci. U.S. 69,581-584.

Perutz, M. F., Muirhead, H., Cox, J. M., and Goaman, L. C. G. (1968), Three-dimensional Fourier Synthesis of Horse Oxyhaemoglobin at $2.8 \AA$ Resolution: The Atomic Model,Nature(London) 219,131-139.

Ptitsyn, 0.B. (1969), Statistical analysis of the distributionof amino acid residues among helical and nonhelical regions in globular proteins, J. Mol. Bid. 42,501510.

Quiocho, F. A., and Lipscomb, W. N. (1971), Carboxypeptidase A: a protein and an enzyme. Adv Protein Chem., 25:1-78.

Shotton, D. M., and Watson, H. C. (1970), Three dimensional structure of tosyl-elastase, Nature (London) 225,811-816.

Wright, C. S., Alden, R. A., and Kraut, J. (1969), Structure of subtilisin $\mathrm{BMN}$ at $2.5 \mathrm{~A}^{\circ}$ resolution, Nature (London)221,235-242.

Wu, T.T., and Kabat, E. A.(1971),An Attempt to Locate the Non-helical and Permissively Helical Sequences of Proteins: Application to the Variable Regions of Immunoglobulin Light and Heavy Chains, Proc. Natl. Acad. Sci. U.S. 68(7), 1501-1506.

Wu, T. T., and Kabat, E. A. (1973),An attempt to evaluate the influence of neighboring amino acids $(n-1)$ and $(n+1)$ on the backbone conformation of amino acid (n) in proteins. Use in predicting the three-dimensional structure of the polypeptide backbone of other proteins, J. Mol. Bid. 25;75(1):13-31.

Wyckoff, H. W., Tsernoglou, D., Hanson, A. W., Knox, J. R., Lee, B., and Richards, F. M. (1970), The threedimensional structure of ribonuclease-S, J.Bid. Chem. 245, 305-328.

Zimm, B. H., and Bragg, J. K. (1959), Theory of the Phase Transition between Helix and Random Coil in Polypeptide Chains, J. Chem. Phys. 31, 526-531. 